\title{
Practice what you preach: Microfinance business models and operational efficiency
}

Citation for published version (APA):

Bos, J. W. B., \& Millone, M. M. (2013). Practice what you preach: Microfinance business models and operational efficiency. Maastricht University, Graduate School of Business and Economics. GSBE Research Memoranda No. 067 https://doi.org/10.26481/umagsb.2013067

Document status and date:

Published: 01/01/2013

DOI:

10.26481/umagsb.2013067

Document Version:

Publisher's PDF, also known as Version of record

\section{Please check the document version of this publication:}

- A submitted manuscript is the version of the article upon submission and before peer-review. There can be important differences between the submitted version and the official published version of record.

People interested in the research are advised to contact the author for the final version of the publication, or visit the DOI to the publisher's website.

- The final author version and the galley proof are versions of the publication after peer review.

- The final published version features the final layout of the paper including the volume, issue and page numbers.

Link to publication

\footnotetext{
General rights rights.

- You may freely distribute the URL identifying the publication in the public portal. please follow below link for the End User Agreement:

www.umlib.nl/taverne-license

Take down policy

If you believe that this document breaches copyright please contact us at:

repository@maastrichtuniversity.nl

providing details and we will investigate your claim.
}

Copyright and moral rights for the publications made accessible in the public portal are retained by the authors and/or other copyright owners and it is a condition of accessing publications that users recognise and abide by the legal requirements associated with these

- Users may download and print one copy of any publication from the public portal for the purpose of private study or research.

- You may not further distribute the material or use it for any profit-making activity or commercial gain

If the publication is distributed under the terms of Article $25 \mathrm{fa}$ of the Dutch Copyright Act, indicated by the "Taverne" license above, 
Jaap W.B. Bos, Matteo Millone

Practice what you preach: Microfinance business models and operational efficiency

RM/13/067

\section{GSBE}

Maastricht University School of Business and Economics

Graduate School of Business and Economics

P.O Box 616

NL- 6200 MD Maastricht

The Netherlands 


\title{
Practice What You Preach: Microfinance Business Models and Operational Efficiency
}

\author{
By JaAp W.B. Bos, Matteo Millone*
}

The microfinance sector is an example of a sector in which firms with
different business models coexist. Next to pure for-profit microfinance
institutions (MFIs), the sector has room for non-profit organizations,
and includes 'social' for-profit firms that aim to maximize a double bot-
tom line and do well while doing good. We introduce a benchmarking
approach that accommodates these three business models and allows us
to estimate the efficiency of MFIs when they operate true to their busi-
ness model, but also when they drift away from their original design.
Using a simple model, we hypothesize that it is more difficult to operate
efficiently when pursuing a double bottom line. Our empirical results
for a large sample of MFIs are in line with this hypothesis: pure for-profit
and non-profit FMIs are more efficient than 'social' for-profit MFIs. In
addition, efficiency decreases for all MFIs when they move away from
their original business model. Increasing the risk of the loan portfolio
reduces efficiency and lending to woman increases efficiency. Finally,
our finding that multiple lending to borrowers is efficiency-enhancing
may help explain the mission drift in microfinance. JEL: G21;O12;O16;C1

Keywords: microfinance; output distance function; social responsibility; sustainability

\footnotetext{
* Bos: Maastricht University School of Business and Economics, P.O. Box 616, 6200 MD, Maastricht, The Netherlands, j.bos@maastrichtuniversity.nl. Millone: Maastricht University School of Business and Economics, P.O. Box 616, 6200 MD, Maastricht, The Netherlands, m.millone@maastrichtuniversity.nl. We are grateful to Luis Orea, participants of the 2012 North American Productivity Workshop in Houston, the 2012 SIRP Mistra Annual Workshop in Paris, participants and discussant and the 2012 Australasian Banking and Finance Conference in Sydney, the 2013 Financial Globalisation and Sustainable Finance Conference in Cape Town, the Third European Research Conference on Microfinance in Kristiansand, and seminar participants at Maastricht University and University of Queensland for helpful comments and discussions. The usual disclaimer applies.
} 


\section{Introduction}

At the center of the current debate about the future of microfinance, is the question whether microfinance institutions (MFIs) should be profit-oriented, privately funded, self-sustaining businesses or socially minded, subsidized, nonprofit organizations (Morduch, 2000). The discussion revolves around the oftenimplicit disagreement regarding how MFIs can operate most efficiently, and with that the lack of consensus regarding what constitutes operational efficiency in microfinance in the first place. Should MFIs be compared based on their profitability or based on their outreach, i.e., the extent to which they provide financial services to those that were previously deprived of these services? The answer to that question is important, as it helps MFIs direct efforts to improve their performance and informs (institutional) investors and donors regarding MFIs' (relative) performance.

Taken at face value, however, it appears that in the microfinance industry, there may be room for more than one business model. For profit (FP) and non-profit (NFP) firms coexist, and increasingly in the same (regional) market. As the microfinance industry has spread across the globe, MFIs have begun to span the entire gamut between pure profit maximization and outreach. Moreover, whereas some non-profit institutions have proven to be more profitable than for-profit institutions, the latter sometimes outclass their for-profit peers when it comes to outreach. Hence, it appears that microfinance accommodates not just two very different business models (profit maximization, outreach maximization), but also different mixtures of these business models.

The coexistence of these business models has and will shape the evolution of the microfinance industry. In any market where for-profit and non-profit firms coexist, questions about fairness, efficiency and competitiveness arise. And views differ. Whereas some argue that non-profit firms can arise endogenously in a neoclassical setting (Lakdawalla and Philipson, 2006) and may help overcome an existing market failure (Hirth, 1999), others argue against comparing for-profit and non-profit firms against the same (neoclassical) benchmark (Pauly, 1987), instead suggesting that utility maximization rather than profit maximization explains behavior in markets with mixed preferences (Lin, Dean and Moore, 1974).

At the heart of this discussion lies a lack of consensus about the nature of the production process in these markets. Do for-profit and non-profit firms produce in the same way, or is it for example the case that the latter can benefit from positive self selection and can acquire inputs such as labor at a cheaper cost, thus compensating for their lack of pure profit maximization (Handy and Katz, 1998)? What we know is that the (non-)existence of a common benchmark is important, as benchmarks (or best practice) creates strong incentives (Bogetoft, 1994). We also know that the notion of utility maximization is not necessarily incompatible with pure profit maximization (Kroll, Levy and Markowitz, 1984), and that the observed choices of firms with different preferences are likely to re- 
flect their utility functions (Smith, 1976). As Leibenstein $(1966,1978)$ argued and Stigler (1976) contested, firms with different preferences can have a common benchmark but show differences in performance as a result of effort discretion and non-maximizing behavior (Perelman, 2011). It is Leibenstein's notion of the resulting $X$-inefficiency that we employ to assess the viability of different business models in microfinance.

In this paper, we argue that MFIs have heterogenous preferences: some only care about financial performance, whereas others are mostly oriented towards social performance (i.e., outreach). Others are, quite literally, somewhere in between. Our view of MFIs allows us to develop and estimate a simple model where institutions produce an output that maximizes financial performance (yield), an output that maximizes depth of outreach (average loan size) and an output that maximizes the breadth of outreach (the number of loans). ${ }^{1}$ Since our production model also includes MFIs' inputs (labor, capital), our approach allows us to ask a number of important questions.

First, we ask whether and to what extent there is a trade-off between each objective (i.e., each output), assuming that all inputs have been used efficiently. At the production frontier, how much depth of outreach has to be sacrificed for a higher yield? Is it possible to combine increases in the depth of outreach, i.e., small average loan size, with a wider breadth of outreach? Our paper contributes to the literature by estimating these tradeoffs while controlling for existing slack in MFIs' production in either direction. Doing so is important, as we may otherwise over- or under-estimate trade-offs: think for example of an MFI that is trying to maximize outreach (depth and width), but does so rather poorly. Not accounting for that poor performance would lead to an overestimation of the trade-off between financial and social performance.

Second, we ask whether the operational efficiency of MFIs depends on their revealed preferences. Are MFIs that are purely profit maximizers more efficient than MFIs that try to maximize outreach? Is there an optimal balance between either objective? Our paper contributes to the literature by estimating the efficiency of MFIs in a setting that accommodates their multi-output nature. Measuring efficiency in this setting is important, as it allows both MFIs, investors and donors to benchmark institutions given their focus on financial performance, social performance or a mix of both. For example, an institutional investor wishing to invest in microfinance as part of its CSR strategy can invest in the most efficient among the MFIs that focus on outreach.

Third, and related, we ask how MFIs can become more efficient. After all, the investor mentioned in the above example can also choose to invest in an inefficient MFI, opting to boost its efficiency through engagement. How should it do so? Is lending to women indeed a good way to increase outreach (Dowla and Barua, 2006)? What is the nature of the risk-return relationship in microfinance

\footnotetext{
${ }^{1}$ In the microfinance literature, the focus on financial revenues is seen as a decrease in the affordability of the loans and increasing loan size is referred to as mission drift.
} 
(Mersland and Strøm, 2009)? What is the effect of disbursing multiple loans per client (Krishnaswamy, 2007)? Our paper addresses these issues in a coherent framework, measuring the effects of operational changes and uncovering the different business models that appear to explain the performance of different types of MFIs. Importantly, our analysis can help repudiate the claim that a panacea exists to 'fix' microfinance: what may work for one institution may not work for another one. However, institutions with a similar output mix may be able to learn from industry best practices.

In order to answer each of these questions, we estimate a multi-output, multiinput production frontier. We use an output distance model (Cuesta and Orea, 2002), control for unobserved institutional differences using a 'true fixed effects' stochastic frontier model (Greene, 2005a), and condition efficiency on a number of choice variables following Battese and Coelli (1988). We use the Microfinance Information Exchange (MIX) data, and compare 1,146 MFIs over the period from 2003 to 2010. Our analysis encompasses both strictly for-profit MFIs and firms with a social mission.

Our results show that mission drift does not only decrease depth, but also breadth of outreach, as evidenced by the negative output elasticity of average loan size with the number of loans. In fact, this negative relationship becomes more pronounced as the average loan size increases. Interestingly, on average, larger loans will result in a lower yield on the gross loan portfolio. Larger loans are also correlated with higher personnel and financing costs. We find support for this finding in the literature, as Mersland (2009) shows that the lower operating costs reported by for-profit MFIs are just an artifice of larger loans. As a matter of fact NGOs have lower costs per loan. According to Gutiérrez-Nieto, Serrano-Cinca and Molinero (2007a), NGOs that rely on voluntary work have low personnel costs and thus are able to efficiently offer a large number of small loans.

In addition, we find that, contrary to Hermes, Lensink and Meesters (2011), MFIs can indeed combine the depth and breadth of outreach, and operate with above average levels of efficiency. However, efficiency quickly decreases with the loan portfolio. These findings are in line with the theoretical predictions of Mersland (2009): NGOs and credit cooperative are more efficient as they are able to lower the costs of market contracts. Such institutions are not profit maximizers and mainly operate via group loans, this makes them better equipped to cope with highly inefficient markets and asymmetric information. Roberts (2012) shows empirically that a stronger profit orientation leads to higher interest rates, but is also associated with higher costs.

Finally, we find that lending to women and repeated lending increases efficiency, whereas increasing the overall riskiness of the loan portfolio has a negative effect on efficiency. The former finding contradicts Cull, Demirg-Kunt and Murduch (2007) and Mersland and Strøm (2011) who show that MFIs that focus on lending to women are respectively less profitable and less efficient. 
The remainder of this paper continues as follows. In Section II, we review the existing literature on microfinance and the performance of MFIs. In Section III, we introduce our analytical framework, empirical model and estimation strategy. In Section IV, we discuss our data set. Section V contains our results. We conclude in Section VI.

\section{Business Models in Microfinance}

Once considered the panacea for pulling the un-bankable out of poverty, microfinance has recently come under heavy scrutiny from the public, the media and regulators. The limits of the model developed by Mohammed Yunus are not new to the academic literature. Issues of sustainability, trade-offs between social and financial goals and more recently, efficiency have been the subject of extensive research by both academics and practitioners. The body of research on microfinance is, nevertheless, very heterogeneous in terms of objectives, methodologies and empirical techniques. In this section, we review some of the main findings.

Morduch (1999b), in questioning the self-reported success of Grameer Bank, is one of the first to challenge the notion of microfinance as a sustainable solution to poverty. When taking a closer look at the bank's financial reports, he finds that the repayment rates are not as good as they claim to be. Furthermore, he finds that, despite reporting profits, Grameer has constantly been subsidized. The findings of Morduch call into question the idea of microfinance as a profitable and yet socially oriented business.

The original view on microfinance was that MFIs following traditional, good banking practices would be the best at alleviating poverty. Morduch (1999a) shows that the 'win-win' proposition is not realistic, both logically and empirically. Given the high costs of lending to the poor, the double bottom line proposition can be sustained only if poor borrowers strictly care about access to and not about the cost of credit (Morduch, 2000). Acknowledging that microfinance cannot be profitable and fully socially oriented at the same time is at the origin of what Morduch defines as 'the microfinance schism.'

From that point onwards, the debate on the role and the future of microfinance is dominated by two contrasting views: institutionalist and welfarist (Brau and Woller, 2004). Whereas both views assume that there is a trade-off between financial and social performance, they draw different inferences. The institutionalist view claims that in order to successfully provide financial services to the poor it is necessary to prioritize financial sustainability. The welfarist view focuses on social performance and considers the reliance on donations as necessary and justifiable, given the poverty reduction mission of MFIs.

The trade-off between financial and social performance itself, is mainly attributed to the higher costs of giving out smaller loans. Von Pischke (1996) distinguishes between demand and supply side effects. On the demand side, as the breadth of outreach increases, the probability of lending to risky borrowers 
increases as well, resulting in an overall riskier portfolio, with more defaults. On the supply side, smaller loans will lead to higher costs, both fixed and variable. This is a consequence of the fact that micro loans are information intensive and have high monitoring costs (Conning, 1999). Fixed costs are not a problem for sustainability as they can be lowered with economies of scale. Variable monitoring costs could be covered by higher interest rates, but this might worsen repayment rates. Poorer borrowers require smaller and more expensive loans that will in turn decrease profitability.

Discussions about the trade-off between financial and social performance gained momentum as a result of mission drift, i.e., the observed tendency of MFIs to move toward richer borrowers by disbursing larger loans. Copestake (2007) frames the decision in the context of a production possibility frontier, where an increase in size leads to economies of scale, allowing the MFI to focus on both depth and breadth of outreach. Since his model is dynamic, a current decrease in social performance may justify an increase in the size of an MFI in the near future. According to Ghosh and Tassel (2008), mission drift itself is the inevitable response of effective MFIs to the entry of profit-oriented investors in microfinance. Gonzalez (2010) and Mersland and Strøm (2010) show that larger loans indeed reduce operating expenses and increase profits.

Nevertheless, empirically testing the trade-off between financial and social performance poses a number of challenges. First, it is hard to distinguish between mission drift and cross-subsidization (Armendáriz and Szafarz, 2010). Second, a decrease in loan size often leads to higher interest rates. According to Mersland and Strøm (2011), "[T]he balance between outreach to the poor and financial sustainability is to a large extent a question of charging sustainable levels of interest rates since the cost of lending small amount is relatively high" (Mersland and Strøm, 2011, p.3). They show that MFIs do not exercise monopoly power and that the high levels of interest rates are caused by increases in input prices and not by high margins. Cull, Demirg-Kunt and Murduch (2007) find a trade-off between the size and number of loans disbursed, and show that even if smaller loans have higher interest payments, they do not have lower repayment rates.

Meanwhile, the trade-off may depend on institutional characteristics, and can therefore differ from one MFI to the next. Mersland and Strøm (2009) look at the effects of corporate governance on the performance of MFIs. They find that most corporate governance characteristics and ownership structures have very limited or no influence on measures of outreach and financial performance. Cull and Spreng (2011) analyze the case of the privatization of the National Bank of Commerce in Tanzania. They show that even if privatization was difficult, it has led to increases in efficiency while maintaining the same level of outreach. In this particular case outreach and efficiency are not negatively related.

A number of papers look more specifically at efficiency using Data Envelopment Analysis (DEA) and Stochastic Frontier Analysis (SFA). Gutiérrez-Nieto, 
Serrano-Cinca and Molinero (2007b) use multivariate DEA models to measure efficiency of MFIs, finding relevant effects of country and NGO status. Similarly Gutiérrez-Nieto, Serrano-Cinca and Molinero (2007a) show the importance of social efficiency assessment. Bassem (2008), uses a sample of mediterranean MFIs to show that size has a negative impact on efficiency. Nawaz, Hudon and Basharat (2011) confirm the result of Hassan and Sanchez (2009) showing on one hand that MFIs with bank status specializing in individual lending tend to be financially efficient and on the other hand that unregulated NGOs are more socially efficient. Model specification is therefore critical in applications of DEA as it is evident in Haq, Skully and Pathan (2010), who show that under the production approach NGOs are more efficient while bank-microfinance institutions are the best performers under the intermediation approach. Hermes, Lensink and Meesters (2011) use a stochastic frontier production model to see whether depth of outreach is related to inefficiency. They find that smaller loan size leads to a decrease in efficiency.

Summing up, although we have come a long way in improving our understanding of the performance of MFIs, important questions have remained unanswered. In the presence of inefficiency, what is the trade-off between financial and social performance for inefficient MFIs? Is there a trade-off between breadth and depth of outreach? How do lending choices affect operational inefficiency, and thereby the trade-off? In order to answer these questions, we now introduce our approach to model and analyze MFIs' performance.

\section{Methodology}

In this section, we introduce our approach to modeling the dual objectives (profit-maximization, outreach) of MFIs. As the literature review in the previous section has shown, the potential trade-off between these objectives has been analyzed at length. Our approach differs from earlier work because we start from the premise that different institutions have different revealed preferences regarding whether to maximize social or financial performance. In our model, an MFI is not penalized for preferring one objective over the other. Rather, an MFI is penalized (i.e., it is inefficient) if it is less successful than other MFIs with the same revealed preferences.

Before we introduce our empirical specification in Section III.C, we first revisit the notion of a trade-off between financial and social performance in microfinance. In Section III.B, we explain how we capture those trade-offs with banks' production set, consisting of a mix of outputs and inputs.

\section{A. Preferences and output mixes in microfinance}

Our objective is to model the production and efficiency of firms with heterogenous preferences. We assume that all firms have access to the same technology and produce the same outputs, albeit in different proportions. Also, we assume 
that the transformation is (weakly) separable in outputs. As a result, output choices are assumed to result from preferences, since the utility firms derive from a certain output set depends on these preferences.

For $M$ inputs, $N$ outputs and a transformation function $T$ that satisfies the usual conditions (Färe and Primont, 1995), we define:

$$
T=\left\{(\mathbf{X}, \mathbf{Y}): \mathbf{X} \in \Re_{+}^{M}, \mathbf{Y} \in \Re_{+}^{N}, \mathbf{X} \text { can produce } \mathbf{Y}\right\} .
$$

Now let us consider both elements in the transformation process: the output vector $\mathbf{Y}$ and the input vector $\mathbf{X}$. First, we focus on $\mathbf{Y}$. We assume that the production of an MFI is weakly separable in outputs: an MFI can choose each of its outputs, but reductions in outputs are proportional, i.e., it is not possible to reduce one of the outputs while keeping the others constant. Furthermore, we assume that within the set of possibilities allowed by the transformation function, the output mix is determined by the preferences of the MFI.

Since we are interested in comparing the efficiency of many MFIs, we can simplify our exposition by normalizing the outputs in the vector $\mathbf{Y}$, dividing each output by the maximum value taken by any of the MFIs with the same input vector $\mathbf{X}$. For the resulting scalar $\hat{\mathbf{Y}}$, we assume that the management of an MFI $i$ values its output mix with the following CES utility function (Dino, 2000):

$$
U_{i}=\frac{\sum_{n=1}^{N} \theta_{n, i} \hat{y}_{n, i}^{1-\rho_{i}}}{1-\rho_{i}},
$$

where lower-case denotes logged variables, $\Sigma_{n=1}^{N} \theta_{n, i}=1$ and $\rho_{i} \geq 0 .^{2}$ For now, we assume that each MFI produces two outputs: $\hat{y}^{N P}$ and $\hat{y}^{F P}$. For FP MFIs, we assume that $\theta_{F P} \geq \theta_{N P}$, and for NP MFIs, we assume that $\theta_{F P}<\theta_{N P}$.

In addition, we assume that $\rho^{N P} \geq \rho^{F P}$; whereas $F P$ MFIs may have entered because of various reasons (diversification, green washing, etc.), NP MFIs are assumed to have a more stringent mission. ${ }^{3}$ Since the parameter $\rho$ presents the degree of aversion against a balanced output mix, what can we learn about the utility of MFIs?

To answer that question, let us start by considering NP MFIs. These MFIs are assumed to be highly averse to a balanced output mix, and will give a higher weight to the NP output in their utility function. Therefore, not surprisingly, $N P$ MFIs strictly prefer output mixes with higher weights for $\hat{y}^{N P}$. Does this mean that FP MFIs strictly prefer output mixes with higher weights for $\hat{y}^{F P}$ ? Not necessarily. To see why, let us first consider 'pure' FP MFIs, who are also

\footnotetext{
${ }^{2}$ By choosing the CES function, we assume that for each MFI $\frac{\partial U_{i}}{\partial y_{n, i}}>0$ and $\frac{\partial^{2} U_{i}}{\partial^{2} y_{n, i}}<0$.

${ }^{3}$ In a comprehensive study, Malani, Philipson and David (2003) paper investigate several reasons why nonprofit firms coexist with for-profit firms. They find that evidence in favor of altruism weakly trumps evidence in favor of non-contractable quality. According to both theories, NP firms put less emphasis on pure profit making, in line with our assumptions made here.
} 
assumed to be highly averse to a balanced output mix and, will give a higher weight to the $F P$ output in their utility function. As a result, for these MFIs things are also clear-cut, and they strictly prefer output mixes with higher weights for $\hat{y}^{F P}$, making them the antithesis of NP MFIs.

Table 1-: Utility, preferences and output mixes

\begin{tabular}{llll}
\hline Type of MFI & Aversion & Preference & Utility ranking \\
\hline NP MFI & $\rho>0$ & $\theta^{N P}>\theta^{F P}$ & $U^{N P}\left(\tilde{\theta}^{N P}>\tilde{\theta}^{F P}\right)>U^{N P}\left(\tilde{\theta}^{N P}=\tilde{\theta}^{F P}\right)>U^{N P}\left(\tilde{\theta}^{N P}<\tilde{\theta}^{F P}\right)$ \\
pure FP MFI & $\rho>0$ & $\theta^{N P}<\theta^{F P}$ & $U^{F P}\left(\tilde{\theta}^{N P}>\tilde{\theta}^{F P}\right)<U^{F P}\left(\tilde{\theta}^{N P}=\tilde{\theta}^{F P}\right)<U^{F P}\left(\tilde{\theta}^{N P}<\tilde{\theta}^{F P}\right)$ \\
'social' FP MFIs & $\rho \geq 0$ & $\theta^{N P} \leq \theta^{F P}$ & $U^{F P}\left(\tilde{\theta}^{N P}>\tilde{\theta}^{F P}\right) \leq U^{F P}\left(\tilde{\theta}^{N P}=\tilde{\theta}^{F P}\right) \leq U^{F P}\left(\tilde{\theta}^{N P}<\tilde{\theta}^{F P}\right)$ \\
\hline Note: $\theta^{F P}$ and $\theta^{N P}$ are the actual weights from the MFI's utility function, whereas $\tilde{\theta}^{F P}$ and $\tilde{\theta}^{N P}$ are the weights \\
resulting from the actual output mix.
\end{tabular}

Things change, however, when we consider 'social' FP MFIs, who want to do well by doing good and as a result are not averse to a balanced output mix. Depending on their preferences, the preferences of their stakeholders and the extent to which the need to make a profit becomes a binding constraint, 'social' FP MFIs give equal weight to the $N P$ output and the $F P$ output, or put (slightly) more weight on the FP output. So with what output mix do 'social' FP MFIs maximize their utility? In case there is uncertainty about $\rho$ and the output weights, the answer, as can be seen in Table 1, is not clear. Summing up, therefore, it would appear that it is much easier for both NP MFIs and 'pure' FP MFIs to know when and where to exert effort in order to optimize their output mix and maximize their utility than it is for 'social' MFIs.

In Figure 1, we show the production possibilities set for a given input mix and transformation function. Every point on the production possibilities frontier represents an efficient combination of $\hat{y}^{F P}$ and $\hat{y}^{N P}$. Any combination of $\hat{y}^{F P}$ and $\hat{y}^{N P}$ lying under the frontier is inefficient.

From Figure 1, we observe the output mixes of the three different groups of MFIs we have previously identified. NP MFIs focus on serving the poor and therefore opt for a relatively high share for $\hat{y}^{N P}$. Pure FP MFIs mainly aim to maximize profits, are more likely to be accused of mission drift, since they opt for a relatively high share for $\hat{y}^{F P}$. And finally, social FP MFIs aim to do well by doing good and consequently have the most 'balanced' output mix.

\section{B. Preferences and production sets in microfinance}

The next step is to establish what constitutes this output mix. We start from the premise that total output $Y$ for an MFI is the value added of the gross loan 
Figure 1. : Efficiency, preferences and output mixes

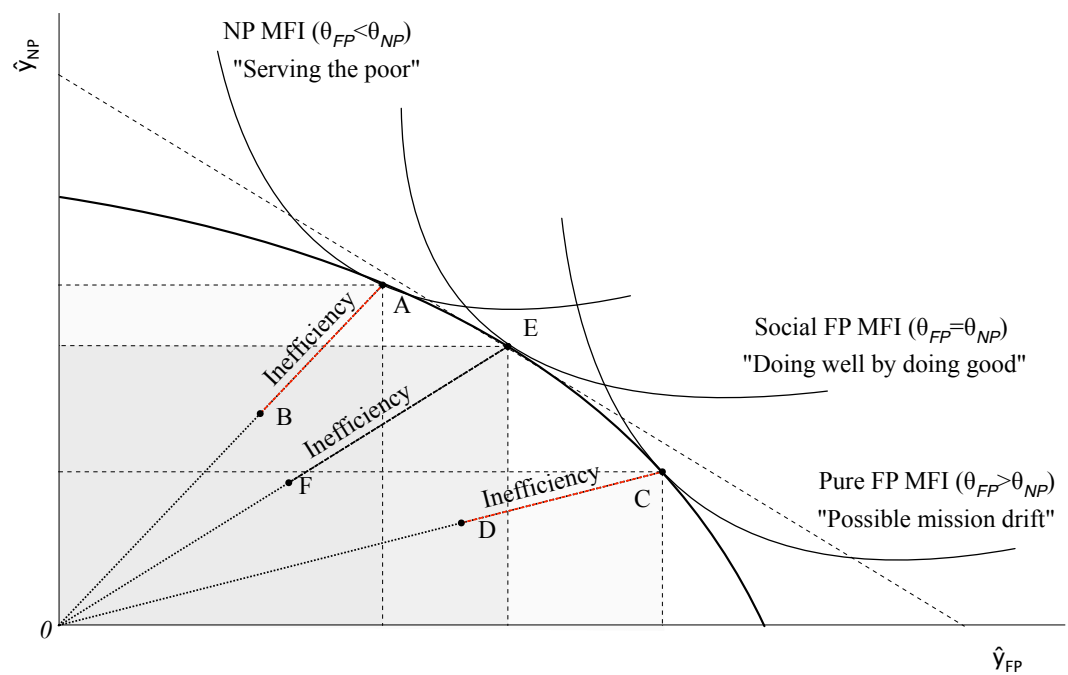

Note: Inefficiency of an MFI located in $B$ is defined as $\frac{B A}{0 A}$. Same for MFIs located in $F$ and $D$. An MFI located on the frontier is efficient.

portfolio. We can then decompose $Y$ as follows:

$$
Y \equiv \underbrace{\frac{R_{y}}{1}}_{\text {Yield }\left(R_{y}\right)} \cdot \underbrace{\frac{G L P}{N L}}_{\text {Average loan size }(A L S)} \cdot \underbrace{\frac{N L}{1}}_{\text {Number of loans }(N L)}
$$

where $R_{y}$ is the average yield on a loan, $N L$ is the number of loans, and $A L S$ is the average loan size.

Increasing the number of loans $(N L)$, enhances the breadth of outreach, making microcredit available to a larger pool of borrowers. Lowering the average loan size $(A L S)$ increases the depth of outreach, making microcredit affordable to poorer borrowers. Of course the affordability of microcredit also depends on its price. The higher the yield on its gross loan portfolio $\left(R_{y}\right)$, the more profitable an MFI will be.

For now, let us focus on average loan size and the number of loans. Obviously, MFIs can have the same gross loan portfolio, but very different mixes: one MFI may opt for a portfolio consisting of a small number of large loans, whereas another MFI may opt for a portfolio consisting of many small loans. In the presence of economies of scale, a higher average loan size will increase profitability, whereas a lower average loan size is traditionally seen as an increase in the depth of outreach. Recent research (Gonzalez, 2010; Mersland and Strøm, 2010; Hermes, Lensink and Meesters, 2011) shows that loan size is positively correlated with profits and negatively with operating costs. Keeping the level of funding 
constant, MFIs that focus on social performance (outreach) will disburse a larger amount of smaller loans compared to fewer larger loans offered by financially oriented institutions. A higher number of loans therefore means an increase in the breadth and depth of outreach, whereas a larger average loan size is often argued to decrease outreach, reflecting mission drift (Ghosh and Tassel, 2008).

For now, if we frame the possible trade-off between average loan size and number of loans as the choice between $\hat{y}^{F P}$ and $\hat{y}^{N P}$ in Figure 1, we first note that the shaded areas in that figure represent the size of an MFIs gross loan portfolio. In the figure, the 'social' FP MFI maximizes the size of its loan portfolio. The NP MFI has a portfolio that is somewhat smaller, but contains more, smaller loans. The 'pure' FP MFI also has a somewhat smaller portfolio, consisting of fewer, larger loans.

Our second, and related observation is that in comparing MFIs in the manner as displayed in Figure 1, we indeed account for the fact that they may have different preferences. If an MFI is producing at point $A$ or $C$, we will consider it as efficient even if the GLP is maximized at point $E$. If fact both $A$ and $C$ are optimal given the shape of the utility function. Higher costs are the result of the decision to prioritise the number of loans rather than the loan size, this cannot be considered an inefficiency. Points $B$ and $D$ represent instead inefficient output mixes, because at each of these points one output dimension could be increased without reducing the other.

Third, since $Y=F(X)$, we note that we can rewrite equation (3) as $A L S=$ $\frac{f(X)}{R_{y} \cdot N L}$. It is straightforward to see that $\frac{\partial A L S}{\partial N L}=-\frac{1}{N L^{2}} \frac{f(X)}{R_{y}}$, which explains the curvature in Figure 1. ${ }^{4}$

Of course, in Figure 1 we compare output choices given an MFI's input mix. In line with the intermediation approach that has become the standard in the banking literature (Sealey and Lindley, 1977), we assume that an MFI uses three inputs: financial capital (funds), physical capital (buildings, equipment, etc.) and labor (personnel). These are measured as financial expenses $\left(X_{f i n}\right)$, administrative expenses $\left(X_{\text {phys }}\right)$ and personnel expenses $\left(X_{\text {labor }}\right)$, respectively.

\section{Efficiency of microfinance institutions with heterogenous preferences and output mixes}

What remains then, is the operationalization of our model for a multioutput/multi-input setting, while accounting for and measuring possible inefficiencies. In fact, we can easily build on existing models for this. To start, reconsider equation 1 and let $P(\mathbf{Y})$ denote the set of feasible output vectors for an

\footnotetext{
${ }^{4}$ Note that here we can explain why the relationship between average loan size and the number of loans can be characterized by the down-ward sloping curve in Figure 1. After all, we can rewrite equation (3) as $\frac{G L P}{N L}=A L S=\frac{f(X)}{R_{y} \cdot N L}$. It is straightforward to see that $\frac{\partial A L S}{\partial N L}=-\frac{1}{N L^{2}} \frac{f(X)}{R_{y}}$, which explains the curvature in Figure 1. The same curvature is also crucial for our interpretation of inefficiency: if we take a linear combination between $\hat{y}^{N P}$ and $\hat{y}^{F P}$, then of course MFIs that are in between are inefficient. More specifically, the curvature reflects the fact that their are some limits to free disposability of outputs, and as a result such a linear combination is not (always) feasible (Bogetoft and Wang, 2005).
} 
input vector $\mathbf{X}$. We can then define the distance to the frontier as:

$$
D_{0}(\mathbf{X}, \mathbf{Y})=\min .\left\{\Psi>0: \frac{\mathbf{Y}}{\Psi} \in P(\mathbf{X})\right\}
$$

where equation (4) is non-decreasing, positively linearly homogeneous and convex in outputs, and decreasing in inputs. This so-called distance function takes a value of one if an output combination lies on the production frontier, otherwise its value is less than one, with $D_{0}(\mathbf{X}, \mathbf{Y})$ if $\mathbf{Y} \in P(\mathbf{X})$.

As shown by Cuesta and Orea (2002) and others, $D_{0}(\mathbf{X}, \mathbf{Y})$ is the inverse of the well-known output-oriented Farrell measure of operational efficiency. Therefore, an efficiency measure of one means that an MFI is fully efficient. In order to parametrize equation (4), we need to impose linear homogeneity in outputs, which we can do by scaling each output by one of the outputs. If we then use a translog functional form to represent the technology, and include a series of regulation dummies $\left(D_{\text {legal }}\right)$ to account for different types of institutions as in Hermes, Lensink and Meesters (2011), we can write the output distance function as: ${ }^{5}$

$$
\begin{aligned}
-\ln \left(y_{i t}\right) & =\alpha_{i}+\sum_{k=1}^{3} \alpha_{k} \ln x_{k i t}+\sum_{j=1}^{2} \beta_{j} \ln y_{j i t}^{*}+\frac{1}{2} \sum_{k=1}^{3} \sum_{h=1}^{3} \alpha_{k h} \ln x_{k i t} \ln x_{h i t} \\
& +\frac{1}{2} \sum_{j=1}^{2} \sum_{h=1}^{2} \beta_{j h} \ln y_{j i t}^{*} \ln y_{h i t}^{*}+\sum_{k=1}^{3} \sum_{j=1}^{2} \alpha_{k h} \ln x_{k i t} \ln y_{h i t}^{*} \\
& +\sum_{k=1}^{3} \sum_{\text {legal }=1}^{4} \zeta_{k i} D_{\text {legal }} \ln x_{k i t}+\sum_{j=1}^{2} \sum_{\text {legal }=1}^{4} \tau_{j i} D_{\text {legal }} \ln y_{j i t}^{*}+u_{i t}+v_{i t},
\end{aligned}
$$

where $\ln \left(y_{i t}\right)$ is $\ln \left(A L S_{i t}\right)$ and $y_{j i t}^{*}$ represents Yield ${ }_{i t}$ and $N L_{i t}$, respectively, scaled by $y_{i t}$. The composite error term $u_{i t}+v_{i t}$ consists of a standard noise term noise term, $v_{i t}$, and an inefficiency component $u_{i t} \geq 0$, which is assumed to be i.i.d., with a distribution truncated at $\mu,\left|N\left(\mu, \sigma_{u}^{2}\right)\right|$, and independent from the noise term. ${ }^{6}$ Efficiency is $0 \leq \exp \left\{-u_{i t}\right\} \leq 1$, where $\exp \left\{-u_{i t}\right\}=1$ implies full efficiency.

We include legal dummies interacted with inputs and outputs to capture the fact that MFIs with different legal status may fact different constraints, resulting in different technologies. The direct effect is captured by firm-specific fixed effects $\alpha_{i t}$, measured using Greene's (2005b) true fixed effect frontier estimator.

\footnotetext{
${ }^{5}$ To correct for spurious interaction terms, all variables in the translog have been transformed following the Frisch-Waugh theorem.

${ }^{6}$ In estimating equation (4), we identify the components of the composite error term by re-parameterizing $\lambda$ in a maximum likelihood procedure, where $\lambda\left(=\sigma_{u} / \sigma_{v}\right)$ is the ratio of the standard deviation of efficiency over the standard deviation of the noise term, and $\sigma\left(=\left(\sigma_{u}^{2}+\sigma_{v}^{2}\right)^{1 / 2}\right)$ is the composite standard deviation. The frontier can be identified by the $\lambda$ for which the log likelihood is maximized (see Kumbhakar and Lovell, 2000).
} 
Following Färe and Primont (1996), the output distance function should be non-decreasing in outputs and decreasing in inputs. We can verify whether this holds, by evaluating the sum of the estimated input elasticities: ${ }^{7}$

$$
-\sum_{k=1}^{M} \delta \ln D_{0}\left(y_{i t}, x_{i t}\right) / \delta \ln x_{i t} \text {. }
$$

At the means of outputs and inputs, we expect a value significantly greater than one, indicating increasing scale economies. Likewise, to investigate the presence of trade-offs between MFIs' outputs, we evaluate:

$$
\delta \ln D_{0}\left(y_{i t}, x_{i t}\right) / \delta \ln y_{j t} \text { for } i \neq j,
$$

where a negative value indicates the existence of a trade-off.

Finally, in order to assess how MFIs can become more efficient, we follow Battese and Coelli (1988), and condition $\mu$, the truncation point for the inefficiency distribution, as follows: ${ }^{8}$

$$
\mu_{i t}=\delta_{0}+\delta_{1} \ln \left(\text { Risk }_{i t}\right)+\delta_{2} \ln \left(\text { Balance }_{i t}\right)+\delta_{3} \ln \left(\text { Repeated-Lending }_{i t}\right),
$$

where Risk $_{i t}$ is the percentage of the portfolio at risk, measured as $P A R 30_{i t}$. Gross Loan Portfolio $i t$, where PAR $30_{i t}$ is the percentage of the loan portfolio that has at least one more installment of the principal past due more than 30 days. We condition efficiency on risk, in order to account for the fact that performance may simply reflect risk-taking. Balance ${ }_{i t}$ reflects the fact that at least 50 percent of MFIs' lending is to female borrowers, as part of their mission to support their development. It is measured as the percentage of female borrowers, and is intended to account for the fact that in reaching out to female borrowers, MFIs may constrain their loan portfolio choice, possibly resulting in less efficient output mixes. Finally, we condition on Repeated-Lending ${ }_{i t}$, measured as the average number of loans per borrower. As MFIs rely more on previous borrowers instead of new ones, they might reduce their outreach, but increase their efficiency by cutting screening costs.

Summing up, we have now developed an empirical model that allows us to explore the trade-off between financial performance and social performance, to benchmark the efficiency of MFIs, and to assess the factors that can improve that efficiency. In the next section, we introduce our data.

\section{Data}

We use the data from the Microfinance Information Exchange market (www.mix.org). The MIX dataset collects self-reported balance sheet informa-

\footnotetext{
${ }^{7}$ We add the minus sign for the dependent variable in line with equation (4).

${ }^{8}$ To control for possible multicollinearity, the variables that explain $\mu$ have been orthogonalized.
} 
tion and is widely used in the literature (Cull, Demirg-Kunt and Morduch, 2009; Ahlin, Lin and Maio, 2011; Hermes, Lensink and Meesters, 2011; Roberts, 2012). In total, MIX includes 1,146 MFIs, over the period 2003-2010. After eliminating outliers, we have an unbalanced panel with 3,890 observations. ${ }^{9}$ Table 2 reports mean values, sorted by the legal status of the institution. ${ }^{10}$

Table 2-: Descriptive statistics for different types of MFIs

\begin{tabular}{|c|c|c|c|c|c|c|c|}
\hline & & Bank & Cooperative & NBFI & NGO & Other & Rural Bank \\
\hline \multirow{6}{*}{ 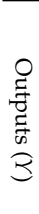 } & Average Loan Balance / GNI & 1.486 & 0.886 & 0.596 & 0.343 & 0.186 & 0.451 \\
\hline & & $(2.588)$ & $(1.021)$ & $(0.791)$ & $(0.607)$ & $(0.149)$ & $(0.372)$ \\
\hline & Number of Loans $(N L)$ & 83065.390 & 14486.311 & 53832.367 & 45667.140 & 2909.500 & 22577.547 \\
\hline & & (115287.906) & (24376.549) & $(117252.275)$ & $(86264.250)$ & $(2860.247)$ & $(36390.681)$ \\
\hline & Yield on gross loan portfolio $\left(Y_{g l p}\right)$ & 0.230 & 0.155 & 0.260 & 0.268 & 0.262 & 0.224 \\
\hline & & $(0.152)$ & $(0.087)$ & $(0.149)$ & $(0.154)$ & $(0.085)$ & $(0.100)$ \\
\hline \multirow{4}{*}{$\begin{array}{l}\vec{E} \\
\stackrel{\vec{Z}}{\vec{E}} \\
\vec{\omega}\end{array}$} & Financial expenses (FiExp/Ass) & 0.058 & 0.053 & 0.058 & 0.048 & 0.103 & 0.050 \\
\hline & & $(0.031)$ & $(0.049)$ & $(0.033)$ & $(0.030)$ & $(0.004)$ & $(0.026)$ \\
\hline & Personnel expenses (PExp/Ass) & 0.084 & 0.054 & 0.102 & 0.114 & 0.122 & 0.067 \\
\hline & & $(0.044)$ & $(0.033)$ & $(0.064)$ & $(0.069)$ & $(0.064)$ & $(0.032)$ \\
\hline$\widehat{\nexists}$ & Administrative expenses (AdExp/Ass) & 0.076 & 0.055 & 0.080 & 0.082 & 0.086 & 0.062 \\
\hline \multirow{7}{*}{ 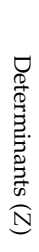 } & & $(0.054)$ & $(0.036)$ & $(0.051)$ & $(0.058)$ & $(0.056)$ & $(0.034)$ \\
\hline & Risk & 0.051 & 0.067 & 0.052 & 0.058 & 0.148 & 0.100 \\
\hline & & $(0.075)$ & $(0.065)$ & $(0.064)$ & $(0.075)$ & $(0.039)$ & $(0.086)$ \\
\hline & Balance & 53.003 & 48.784 & 61.071 & 73.484 & 61.130 & 51.987 \\
\hline & & $(21.475)$ & $(19.882)$ & $(24.441)$ & $(23.046)$ & $(20.761)$ & $(27.815)$ \\
\hline & Multiple lending & 1.069 & 1.067 & 1.053 & 1.051 & 1.000 & 1.059 \\
\hline & & $(0.111)$ & $(0.206)$ & $(0.191)$ & $(0.254)$ & $(0.000)$ & $(0.135)$ \\
\hline \multirow{6}{*}{$\begin{array}{l}8 \\
\frac{p}{\infty}\end{array}$} & Costs per borrower & 297.136 & 233.755 & 231.545 & 130.605 & 105.000 & 107.219 \\
\hline & & $(281.549)$ & $(176.063)$ & $(547.116)$ & $(236.798)$ & $(25.456)$ & (77.837) \\
\hline & Costs per loan & 282.502 & 220.937 & 220.242 & 118.811 & 105.000 & 103.380 \\
\hline & & $(276.426)$ & (166.491) & (538.374) & (129.898) & $(25.456)$ & (77.018) \\
\hline & Total expenses & 23.740 & 17.482 & 25.947 & 26.414 & 33.635 & 18.693 \\
\hline & & $(9.851)$ & $(8.078)$ & $(12.062)$ & $(12.814)$ & $(15.408)$ & $(6.754)$ \\
\hline & Number of observations & 259 & 490 & 1,236 & 1,551 & 14 & 177 \\
\hline
\end{tabular}

Note: Standard deviation in parentheses; all monetary values in USD, corrected for inflation. Cooperative is a cooperative or a credit union; NBFI is a non-bank financial institution; NGO is a non-governmental organisation. Average loan size in USD. Yield on gross loan portfolio: one percent is 0.01 . Inputs are scaled by assets for comparative purposes, but included non-scaled in the estimations of the output distance frontier. Portfolio at risk, 30 days late for payment. Multiple lending is defined as number of loans over number of borrowers. 3,727 observations in total.

The first thing to observe from Table 2, is the large heterogeneity among MFIs. On the one end of the spectrum, we find banks, who are the largest institutions in the sample, offer largest loans and seem to be indifferent between lending to men or women. Despite the fact that banks on average give out large loans,

${ }^{9} \mathrm{We}$ exclude the top and bottom percentiles.

${ }^{10}$ MIX contains MFIs from 101 countries. We control for country effects through firm-specific fixed effects. 
they have relatively high costs per borrower, suggesting that they are not able to benefit from economies of scale. Nevertheless, and consistent with their profit motive, banks have a high yield on gross loan portfolio (although it is not the highest).

On the other end of the spectrum we have rural banks, who despite their small size and small loans have low costs per borrower and a lower yield. Credit unions are the best performers in terms of affordability and profitability, but offer some of the largest loans. Both credit unions and non-bank financial institutions (NBFI) are relatively smaller in size, but NBFIs offer smaller loans, which in turn leads to higher yield on gross portfolio. NGOs are the smallest institutions, offer the smallest loans and almost three quarters of their borrowers are women. The cost per borrower reported by NGOs is one of the lowest, but at the same time the yield on gross portfolio is the highest in the sample.

Based on the descriptive statistics in Table 2, we can observe that it is not obvious that there are economies of scale, since larger institutions do not report lower average costs. Also, for-profit institutions do not report lower total expenses or average costs, invalidating claims of superior management quality. In addition, institutions that offer larger loans tend to charge lower interest rates. Finally, high yields on gross portfolio seem to be unrelated to costs per borrower, but might instead be a consequence of the higher credit risk of smaller loans.

Nevertheless, these results need to be interpreted carefully for two reasons. First, low costs per borrowers reported by NGOs and Rural Banks will be influenced by subsidies, for which we have no data. Second, a significant number of institutions may be operating inside the production possibility frontier and might still be able to improve their performance in multiple dimensions.

The evidence reported in Table 2 supports the empirical specification of our model. It shows that there are indeed strong differences in the gross loan portfolio composition, costs and yield among MFIs. This justifies the use of a production function with multiple outputs. Additionally, the heterogeneity across legal statuses gives reasons for using institution type dummies in the specification of the output distance function.

\section{Results}

We begin this section with a brief description of the estimation of the multioutput, multi-input production frontier. Next, we explore the relationship between the choice of output mix, business models and MFIs' efficiency.

\section{A. Estimation results}

We start by estimating the output distance frontier. Table A.1 in the Appendix contains the estimation results for our output distance frontier model, while Figure 2 below shows the resulting distribution of efficiency. Importantly, we include MFI-specific fixed effects to account for firm- and country-specific condi- 
tions that may affect the production process. ${ }^{11}$

Figure 2. : Distribution of efficiency

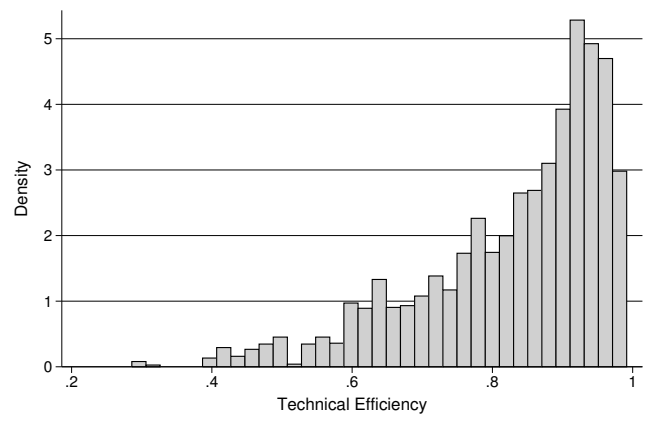

Note: mean efficiency $=0.83$; standard deviation $=0.13$

Before we delve into the implications of these estimation results for different groups of MFIs, a logical first question is whether efficiency matters? In Table A.1, we therefore focus on $\lambda$, the ratio of inefficiency and noise. The estimated $\lambda$ of 2.5600 demonstrates that there is a considerable amount of inefficiency: more than 70 percent of the 'unexplained'variance is the result of efficiency differences. $^{12}$

The resulting efficiency scores are portrayed in Figure 2. On average, MFIs are $83 \%$ efficient, meaning they should be able to produce $17 \%$ more outputs (given their output mix), based on what their peers operating at the frontier are able to produce, with the same input mix. Finally, we observe that efficiency is by no means normally distributed, something we have to take into account later when we do formal testing and when we calculate marginal effects.

\section{B. Analysis}

Now that we have estimated the output distance frontier, we can begin our analysis of the relationship between output mixes, business models and efficiency. We start by exploring the trade-off between financial and social performance. Next, we examine how MFIs' observed output mix is related to efficiency. Subsequently, we find out whether it matters if that output mix is in line with MFIs' business model. Our final exploration concerns the ways in which MFIs can improve efficiency for a given output mix.

\footnotetext{
${ }^{11}$ These fixed effects are not included in Table A.1, but available upon request from the authors. Because of the nature of the translog model, interpreting individual coefficients is notoriously cumbersome. Instead we report input and output elasticities in Table 3 and discuss them in the next subsection.

${ }^{12}$ Since $\lambda=\sigma_{u} / \sigma_{v}$, a $\lambda$ of 2.5600 means that $\sigma_{u} /\left(\sigma_{u}+\sigma_{v}\right)=0.72$.
} 
WHAT IS THE TRADE-OFF BETWEEN FINANCIAL AND SOCIAL PERFORMANCE?

Our description of the production process in Section III suggested that there may be a trade-off between financial and social performance. If the latter is reflected in giving many small loans to the poor, then it may for example result in higher operational costs and lower profit margins. This forces MFIs to raise interest rates resulting in more profitable, but less affordable loans. In the same vein, increasing the size of loans might allow MFIs to cut costs, attract commercial funding and serve more borrowers in the future (Hulme, Mosley et al., 1996; Copestake, 2007). Summing up, the larger the trade-off is, the more it matters whether MFIs produce an output mix that is in line with their business model. And the more the trade-off varies with output levels, the higher the penalty of drifting away from that business model may be.

Table 3-: Output trade-offs and scale economies

\begin{tabular}{|c|c|c|c|}
\hline & Elasticity & Mean & p-value \\
\hline \multirow{2}{*}{$\prec$} & Elasticity with respect to yield on gross loan portfolio $\left(\varepsilon_{Y_{G L P}}\right)$ & -0.195 & 0.000 \\
\hline & Elasticity with respect to number of loans $\left(\varepsilon_{N L}\right)$ & -0.693 & 0.000 \\
\hline \multirow{4}{*}{$x$} & Elasticity to financial expenses & 0.344 & 0.000 \\
\hline & Elasticity to administrative expenses & 0.019 & 0.475 \\
\hline & Elasticity to personel expenses & 0.563 & 0.000 \\
\hline & Scale economies (= total input elasticity) & 0.923 & 0.000 \\
\hline
\end{tabular}

To find out what kind of trade-offs exist in the production process of MFIs, we calculate input and output elasticities from the estimated output distance frontier. The resulting average elasticities are reported in Table 3. From the table, we observe that both the number of loans and the yield on the gross-loan portfolio are substitutes to the average loan size. The output trade-offs in Table 3 confirm our expectations: in changing their output mix, MFIs are on average required to give up some characteristic of their current mix in order to gain in another dimension.

Our results indicate that the MFIs that target the very poor are able to do so only by charging higher interest rates, reflected in the negative elasticity of average loan size to yield on gross portfolio. Consistent with Conning (1999), depth of outreach often comes at the cost of affordability, but as Figure 3a shows for some MFIs the substitution elasticity of average loan size and the yield on the gross loan portfolio is either zero or positive, meaning that they are able to serve the poor without necessarily charging higher interest rates. Finally, we show 
Figure 3. : Output substitution elasticities

(a) Substitution elasticity of average loan size and yield on gross loan portfolio

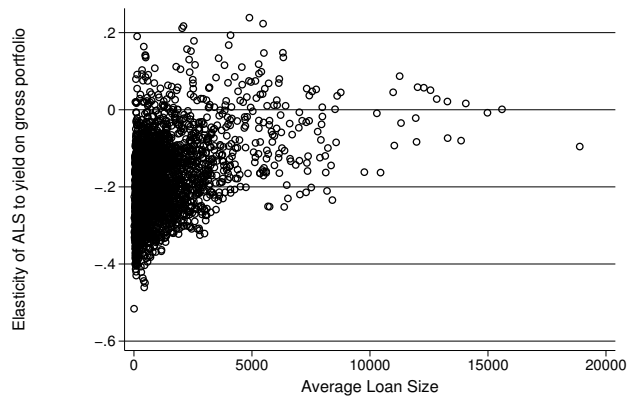

(b) Substitution elasticity of average loan size and number of loans

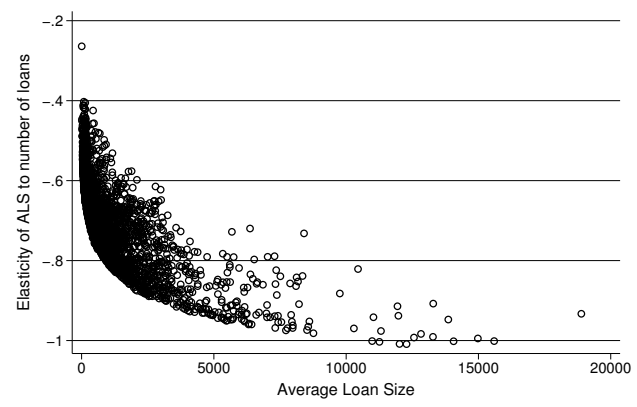

that mission drift always leads to a decrease in breadth of outreach, reflected in the consistently negative substitution elasticity of average loan size and number of loans in Figure 3b. If MFIs want to serve richer clients by disbursing larger loans they are able to so only by reducing the number of loans, a trade-off that becomes even stronger as loan size increases.

The fact that an increase in the the number of loans is accompanied by a smaller average loan size and a higher yield for the gross loan portfolio may to some extent be explained by diseconomies of scale in production. In order to find out whether this is the case, we calculate input price elasticities in the lower half of Table 3. For our translog specification, the sum of these elasticities is a measure of MFIs' scale economies in production. Indeed, we find that on average MFIs experience scale economies that are significantly below unity, indicative of diseconomies of scale, and perhaps the result of the challenges that MFIs face when growing, such as saturated markets, less effective monitoring and lack of adequate human resources (Claudio Gonzalez-Vega, Mark Schreiner, Richard L Meyer, Jorge Rodriguez-Meza and Sergio Navajas, 1997).

Summing up, we find that there are significant trade-offs in the production of MFIs. Next, we find out whether these trade-offs affect the efficiency of different business models.

\section{DOES MFIS' SOCIAL MISSION AFFECT EFFICIENCY?}

Now that we have established that there are significant output mix trade-offs, we can determine whether MFIs' efficiency is affected by the breadth and depth of their outreach. To do so, and to avoid engineering our results, we adopt the same categorization provided by the MIX, and sort MFIs according to their depth 
and breadth of outreach, respectively. ${ }^{13}$ First, we ask whether each (depth and breadth) affects efficiency, then we study the impact of different mixes of depth and breadth of outreach on efficiency.

We start, in Table 4, with a comparison of the level and spread of efficiency for different degrees of outreach. As discussed in the previous section, the efficiency scores are not normally distributed. We therefore use a Kruskal Wallis (KW) rank test to compare differences in levels.

Table 4a focuses on the breadth of outreach, defined as the number of active borrowers. Of course, by construction the concept of breadth of outreach is strongly correlated with the size of the institution. From the KW test statistics, we see that there is no significant difference in efficiency between MFIs with different breadth of outreach, confirming that size and efficiency are not (cor)related. Does this also imply that the ease with which an MFI reaches that average efficiency is not dependent on the breadth of outreach? In order to answer that question, we compare the spread of efficiency scores for different levels of outreach. Our results are straightforward: the higher the breadth of outreach, the more efficiency varies. MFIs that serve a smaller amount of borrowers operate more narrowly around the frontier.

Table 4-: Level of Outreach and Efficiency

(a) Breadth of outreach and efficiency

\begin{tabular}{lccccccccc}
\hline Breadth of outreach & \multicolumn{7}{c}{$\mathrm{N}$} & \multicolumn{6}{c}{ Mean $K W_{(S-M)}$} & $K W_{(M-L)}$ & $K W_{(L-S)}$ & St.Dev & $F_{(S-M)}$ & $F_{(M-L)}$ & $F_{(L-S)}$ \\
\hline Small breadth (S) & 1,670 & 0.841 & 0.621 &. &. & 0.108 & 0.000 &. &. \\
Medium breadth (M) & 988 & 0.826 &. & 0.796 &. & 0.139 &. & 0.000 & . \\
Large breadth (L) & 1,069 & 0.815 &. &. & 0.783 & 0.159 &. &. & 0.000 \\
\hline
\end{tabular}

(b) Depth of outreach and efficiency

\begin{tabular}{lccccccccccc}
\hline Target market & \multicolumn{2}{c}{$\mathrm{N}$} & \multicolumn{1}{c}{ Mean $K W_{(L-B)} K W_{(B-H)} K W_{(H-S)} K W_{(S-L)}$ St.Dev $F_{(L-B)} F_{(B-H)} F_{(H-S)} F_{(S-L)}$} \\
\hline Low end $(L)$ & 1,558 & 0.879 & 0.000 &. &. &. & 0.105 & 0.000 &. &. &. \\
Broad $(B)$ & 1,848 & 0.799 &. & 0.000 &. &. & 0.138 &. & 0.031 &. &. \\
High end $(H)$ & 185 & 0.747 &. &. & 0.176 &. & 0.154 &. &. & 0.337 &. \\
Small business $(S)$ & 113 & 0.776 &. &. &. & 0.000 & 0.133 &. &. &. & 0.000 \\
\hline
\end{tabular}

Note: $K W=$ Kruskal Wallis rank test, $p$-values reported; $F=\mathrm{F}$ test for the homogeneity of variances, $p$-values reported. Depth of outreach, represented by the target market, is measured as average loan balance per borrower/GNI per capita.

In Table $4 b$, we repeat the analysis and look at the efficiency of MFIs with different levels of depth of outreach. Here, we measure the latter, in line with the

\footnotetext{
${ }^{13}$ Depth of outreach is defined as target market by the MIX, the two terms will be used interchangeably. Definition of groups can be found in Table A.2.
} 
categorization of MIX, as on average loan size over per capita Gross National Income (GNI). Importantly, the overwhelming majority of MFIs in our dataset offers loans below 149\% of GNI per capita. The mean efficiency scores clearly show that MFIs that offer larger loans are significantly less efficient. The largest drop in efficiency (of $8 \%$ ) is observed between low end and broad targeting, while there is no significant difference between high end and small business targeting. We can detect the same pattern in the spread of efficiency scores, with a large increase between low end and broad and no significant difference between high end and small business. Thus, for MFIs that focus on the very poor efficiency is not only higher but also more easily achievable.

These results have important implications for the discussion around mission drift as they do not support the claim that MFIs moving upmarket are able to increase efficiency. In fact, if increasing loans size is the response to competition with profit oriented institutions (Ghosh and Tassel, 2008), it is the wrong one. We find opposite results to Hermes, Lensink and Meesters (2011), who do not specifically take into account the multi-output nature of microfinance.

So far, then, our results show that whereas increasing the breadth of outreach does not affect the level of efficiency, increasing the depth of outreach does. Earlier, we found that there is a significant trade-off between breadth and depth of outreach. Combining both results leads to logical next question: what is the optimal mix of breadth and depth of outreach?

Table 5-: Trade-offs in Outreach and Efficiency

\begin{tabular}{|c|c|c|c|c|c|c|c|c|c|}
\hline Target market & Breadth of outreach & N Mean $I$ & $W_{(S-M)}$ & $K W_{(M-L)}$ & $K W_{(L-S)}$ & St.Dev & $F_{(S-M)}$ & $F_{(M-L)}$ & $F_{(L-S)}$ \\
\hline & Small (S) & 5200.882 & 0.000 & & & 0.083 & 0.913 & & \\
\hline \multirow[t]{3}{*}{ Low end } & Medium $(M)$ & 4460.897 & . & 0.052 & . & 0.083 & . & 0.000 & \\
\hline & Large $(L)$ & 5920.861 & . & . & 0.092 & 0.131 & . & . & 0.000 \\
\hline & Small (S) & 9590.828 & 0.000 & $\cdot$ & . & 0.108 & 0.000 & & \\
\hline \multirow[t]{3}{*}{ Broad target } & Medium $(M)$ & 4780.768 & . & 0.401 & . & 0.149 & . & 0.001 & \\
\hline & Large $(L)$ & 4110.768 & . & . & 0.000 & 0.170 & . & . & 0.000 \\
\hline & Small (S) & 850.786 & 0.377 & . & . & 0.130 & 0.896 & & \\
\hline \multirow[t]{3}{*}{ High end } & Medium $(M)$ & 420.759 & . & 0.013 & . & 0.152 & . & 0.044 & \\
\hline & Large $(L)$ & 580.680 & . & . & 0.000 & 0.168 & . & . & 0.003 \\
\hline & Small (S) & 840.775 & 0.491 & & & 0.129 & 0.358 & & \\
\hline \multirow[t]{2}{*}{ Small business } & Medium $(M)$ & 210.791 & . & 0.316 & . & 0.161 & . & 0.167 & \\
\hline & Large $(L)$ & 80.739 & . & . & 0.454 & 0.102 & . & . & 0.118 \\
\hline
\end{tabular}

Note: $K W=$ Kruskal Wallis rank test, $p$-values reported; $F=\mathrm{F}$ test for the homogeneity of variances, $p$-values reported. Depth of outreach, represented by the target market, is measured as average loan balance per borrower/GNI per capita.

To answer this question, we look at the combination of depth and breadth of outreach in Table 5. From that table, we observe that the majority of MFIs no 
longer serve the very poor, but instead supply loans to a broad(er) target. ${ }^{14}$ In line with previous results (Bassem, 2008), we find that for all levels of depth of outreach, MFIs with a low end target are more efficient. In fact, the smallest institutions that serve the poor are still able to operate well above the mean efficiency of $83 \%$. Almost all other MFIs offering larger loans operate below mean efficiency. The least efficient group consists of MFIs with a large number of high end clients, and includes the largest lenders in the sample. Overall, it appears that MFIs with a medium to large breadth of outreach and a high depth of outreach (i.e., serving the low end of the market) are most efficient.

A similar pattern emerges, when we consider the distribution of efficiency. MFIs that serve the poor show the lowest dispersion of efficiency around the frontier. In most cases, the spread of efficiency increases with both the average size of loans and the number of clients. Inefficiencies related to mission drift become more severe as MFIs start serving more borrowers. MFIs offering many large loans should do so because of economies of scale (Copestake, 2007), but appear to pay a price in terms of lower efficiency. A possible explanation is that MFIs in the last two groups (high end and small business) face more competition from traditional banks. A harsher competitive environment means a more saturated market and riskier new borrowers (Gonzalez-Vega et al., 1997).

\section{DOES MFIS' SOCIAL MISSION AFFECT THE TRADE OFF?}

In section III.A and Figure 3, we first hypothesize and then show that output trade-offs vary depending on MFIs' business models. In this section we explore how those trade-offs vary among MFIs with different breadth and depth of outreach and whether this has any influence on efficiency. In Tables 6 and 7, we therefore compare MFIs with different levels of outreach. For each level, we compare firms with an average elasticity of output substitution to those with a high or a low elasticity.

In Table 6, we focus on breadth of outreach. From panel $A$ we see that the majority of MFIs that serve a small number of clients can increase the depth of outreach without large increases in the price of the loans, as a result of low elasticities of substitution. This is to be expected as small MFIs are usually nonprofit or institutions in their infancy and will prefer to offer more affordable loans. Nevertheless when elasticity is lowest for small MFIs, so is efficiency. When the number of clients increases, both funding constraints and competition will increase, leading to less discretion in setting prices for a given loan size. We find evidence of this as the frequency of MFIs operating subject to a high elasticity increases with breadth of outreach.

The story changes in panel $B$, where a high elasticity of substitution is more common for MFIs with small breadth. For this group, with a small loan port-

${ }^{14}$ As yet, however, only a few MFIs serve small businesses. 
Table 6-: Trade Off and Breadth of Outreach

\begin{tabular}{|c|c|c|c|c|c|c|c|}
\hline \multirow[b]{2}{*}{ Breadth of Outreach } & \multirow[b]{2}{*}{ Elasticity } & \multicolumn{3}{|c|}{ A. Yield $\left(Y_{R G P}\right)$} & \multirow[b]{2}{*}{$(\mathrm{KW})$} & \multicolumn{2}{|c|}{ B. Number of Loans (NL) } \\
\hline & & $\mathrm{N}$ & $\varepsilon_{Y_{R G P}}$ & Mean & & $\mathrm{N} \quad \varepsilon_{Y_{N I}}$ Mean & $(\mathrm{KW})$ \\
\hline \multirow{3}{*}{ Small breadth } & Low & 1151 & -0.088 & $0.837^{* * *}$ & $(0.002)$ & $151-0.6150 .919^{* * *}$ & $(0.000)$ \\
\hline & Medium & 480 & -0.193 & 0.849 & & $\begin{array}{lll}450 & -0.699 & 0.887\end{array}$ & \\
\hline & High & 29 & -0.265 & 0.853 & $(0.539)$ & $1059-0.8140 .809^{* * *}$ & $(0.000)$ \\
\hline \multirow{3}{*}{ Medium breadth } & Low & 74 & -0.134 & $0.844^{* * *}$ & $(0.004)$ & $291-0.6110 .922^{* * *}$ & $(0.000)$ \\
\hline & Medium & 617 & -0.212 & 0.810 & & $\begin{array}{lll}543 & -0.691 & 0.801\end{array}$ & \\
\hline & High & 293 & -0.261 & $0.855^{* * *}$ & $(0.000)$ & $150-0.7660 .730^{* * *}$ & $(0.000)$ \\
\hline \multirow{3}{*}{ Large breadth } & Low & 12 & -0.132 & 0.870 & $(0.451)$ & $\begin{array}{lll}795 & -0.568 & 0.839^{* * *}\end{array}$ & $(0.000)$ \\
\hline & Medium & 141 & -0.216 & 0.815 & & $\begin{array}{lll}245 & -0.678 & 0.732\end{array}$ & \\
\hline & High & 916 & -0.302 & 0.814 & $(0.900)$ & $29-0.7650 .845^{* * *}$ & $(0.000)$ \\
\hline
\end{tabular}

Note: $* * / * * *$ signifies significant difference with middle tertile at the $1 / 5 / 10 \%$ level. Kruskal-Wallis rank test for efficiency levels.

folio, any increase in average loan size will result in a much larger decrease in the number of loans disbursed. As the size of the loan portfolio increases, more MFIs are able to relax the relationship between breadth and depth of outreach. As a result, the consequences of mission drift are worst for small MFIs who suffer a large drop in breadth of outreach. The most interesting observation from panel $B$ is that very efficient MFIs are able to operate with a low elasticity of substitution between breadth and depth of outreach, implying that small MFIs are not doomed to operate within narrow boundaries but are able to considerably increase their impact through improvements in efficiency.

Table 7—: Trade Off and Depth of Outreach

\begin{tabular}{|c|c|c|c|c|c|c|c|c|c|}
\hline \multirow[b]{2}{*}{ Target market } & \multirow[b]{2}{*}{ Elasticity } & \multicolumn{4}{|c|}{ A. Yield $\left(Y_{R G P}\right)$} & \multicolumn{4}{|c|}{ B. Number of Loans (NL) } \\
\hline & & $\mathrm{N}$ & $\varepsilon_{Y_{R G P}}$ & Mean & $(\mathrm{KW})$ & $\mathrm{N}$ & $\varepsilon_{Y_{N L}}$ & Mean & $(\mathrm{KW})$ \\
\hline \multirow{3}{*}{ Low end } & Low & 336 & -0.109 & 0.888 & $(0.309)$ & 929 & -0.577 & $0.889^{* * *}$ & $(0.000)$ \\
\hline & Medium & 507 & -0.206 & 0.887 & & 426 & -0.684 & 0.877 & \\
\hline & High & 706 & -0.297 & 0.868 & $(0.444)$ & 194 & -0.778 & $0.830^{* * *}$ & $(0.000)$ \\
\hline \multirow{4}{*}{ Broad } & Low & 755 & -0.085 & $0.826^{* * *}$ & $(0.000)$ & 290 & -0.605 & $0.803^{*}$ & $(0.057)$ \\
\hline & Medium & 634 & -0.204 & 0.786 & & 717 & -0.696 & 0.798 & \\
\hline & High & 457 & -0.284 & 0.771 & $(0.367)$ & 839 & -0.808 & 0.799 & $(0.169)$ \\
\hline & Low & 69 & -0.079 & $0.784^{*}$ & $(0.075)$ & 5 & -0.623 & 0.698 & $(0.881)$ \\
\hline \multirow[t]{3}{*}{ High end } & Medium & 60 & -0.208 & 0.740 & & 80 & -0.693 & 0.706 & \\
\hline & High & 55 & -0.273 & 0.706 & $(0.140)$ & 99 & -0.819 & $0.781^{* * *}$ & $(0.001)$ \\
\hline & Low & 69 & -0.082 & 0.764 & $(0.173)$ & 0 & & & \\
\hline \multirow[t]{2}{*}{ Small business } & Medium & 33 & -0.202 & 0.796 & & 12 & -0.692 & 0.709 & \\
\hline & High & 10 & -0.283 & 0.774 & $(0.863)$ & 100 & -0.842 & 0.782 & $(0.165)$ \\
\hline
\end{tabular}

Note: $* / * * * *$ signifies significant difference with middle tertile at the $1 / 5 / 10 \%$ level. Kruskal-Wallis rank test for efficiency levels.

In Table 7, we look at how MFIs with different depths of outreach are affect 
by changing output trade-offs. We find that as MFIs drift away from serving the poorest, they face a stronger trade off between depth of outreach and the yield on their gross loan portfolio. Within a MFIs with the same target group there is little variation in efficiency. However, efficiency agrees as MFIs start targeting the poor. Moving to Panel $B$, we observe that for the majority of MFIs efficiency decreases as the trade-off with the number of loans increases, mimicking the results from6. Changing target group, however, does not have a strong impact on this observation.

Summing up, we see that MFIs with different business models will, to a large extent, face different trade-offs. In line with Figure 3, we find that MFIs with different mixes of breadth and depth of outreach face very different trade-offs with respect to the yield on gross portfolio. Most importantly, however, very efficient MFIs are able to relax the rigid relationship between breadth and depth of outreach, and - at least along these dimensions - can have the best of both worlds.

\section{CAN MFIS IMPROVE THEIR EFFICIENCY FOR A GIVEN OUTPUT MIX?}

This brings us to our final question: how then can MFIs improve their efficiency for a given output mix? In order to answer that question, we assess the impact of a number of operational choices on MFIs' efficiency. We do so by conditioning the distribution of efficiency scores on three variables that are under the direct control of the management of an MFI. After all, in an increasingly crowded industry such as microfinance, searching for ways to improve efficiency without changing current business may be crucial. Each of the variables we consider relate to a re-balancing of MFIs' loan portfolio, in order to improve operational efficiency.

First, we consider the risk of MFIs' loan portfolio, measured as the dollar amount of the portfolio that has at least one more instalment of the principal past due more than 30 days. The amount of portfolio in default measures portfolio quality and risk attitude of the MFIs. Lenders can increase their portfolio quality by requiring collateral and engaging in more screening and monitoring. Nevertheless, MFIs usually operate in the absence of collateral, in markets where severe information asymmetry makes screening and monitoring very costly. According to Von Pischke (1996), the probability of lending to risky borrowers increases with breadth of outreach. Table 8 contains our estimation results. In the table, we report both the estimated coefficient (for inefficiency), as well as the derived average partial effect on efficiency, following Greene (2007). ${ }^{15}$ From Table 8 , we observe that increasing risk lowers efficiency.

Another way in which MFIs can rebalance their portfolios, is by changing the percentage of women borrowers. Since almost all types of MFIs on average lend

\footnotetext{
${ }^{15}$ Note that the latter can be significant even when the former is not, implying that very high and/or low values of the conditioning variable do not have a significant effect.
} 
Table 8-: Operational determinants of efficiency

\begin{tabular}{|c|c|c|c|c|c|}
\hline \multirow[b]{2}{*}{ Variables } & & \multicolumn{2}{|c|}{ Estimation output } & \multicolumn{2}{|c|}{ Marginal effect on efficiency } \\
\hline & & Coefficient & (Std. error) & Partial effect & (Std. error) \\
\hline Constant & & $-0.9415^{* * *}$ & $(0.2342)$ & & \\
\hline Risk & $\ln ($ PAR30 $\cdot$ GrossLoanPortfolio $)$ & $0.4379^{* * *}$ & $(0.0613)$ & $-0.0071^{* * *}$ & $(0.0027)$ \\
\hline Balance & $\ln (\%$ Women $\cdot$ Borrowers $)$ & $-0.3543^{* * *}$ & $(0.0779)$ & $0.0060^{* * *}$ & $(0.0022)$ \\
\hline Multiple lending & $\ln ($ Loans / Borrowers $)$ & -0.0807 & $(0.0742)$ & $0.0011^{* * *}$ & $(0.0002)$ \\
\hline
\end{tabular}

more than $50 \%$ to women, rebalancing in many cases would involve lowering the share of loans to women. However, the number of women borrowers is an alternative measure of depth of outreach of the MFI (Schreiner, 2002; Hermes, Lensink and Meesters, 2011). From the summary statistics in Table 2 we can observe how NGOs and Rural Banks have comparable level of depth of outreach, but are strongly different when it comes to the percentage of women borrowers. This is an indication of how relevant the original social mission of microfinance is for the institution. Changing the loan portfolio towards woman borrowers, however, increases efficiency. This finding is in line with D'Espallier, Guérin and Mersland (2011) who find that women are better borrowers, but it is not consistent with Hermes, Lensink and Meesters (2011).

Finally, MFIs can change the composition of their loan portfolios through repeat lending. An advantage of granting multiple loans to the same borrower, is the fact that both MFI and borrower can use the relationship they built to lower asymmetric information. A disadvantage, however, is a decrease in outreach, as fewer borrowers receive loans, ceteris paribus. We introduce the ratio of the number of loans to the number of borrowers as a rough measure of the overlending of an MFI. Even if over-indebtedness in microfinance is a hotly debated topic (Schicks, 2010), it is a concept hard to define, let alone measure (Alam, 2012). We simply try to identify institutions that are willing to disburse multiple loans for each borrower. Interestingly, multiple lending has a positive coefficient. This is surprising at first but it might be consistent with the fact that it is cheaper for MFIs to screen and monitor returning borrowers.

Concluding, if MFIs are looking at improving their efficiency without necessarily changing their output mix, they should reduce portfolio risk, increase the number of women borrowers and to a greater extent rely on longer relationships with borrowers.

\section{Conclusion}

The idea behind microfinance is quite simple: to provide financial services to the poor. In reality, its application is everything but simple. As the microfinance sector evolves, it has become an example of a sector in which firms with different business models coexist. Next to pure for-profit microfinance institutions (MFIs), the sector has room for non-profit organizations, and includes 'social' for-profit 
firms that aim to maximize a double bottom line and do well while doing good. We introduce a benchmarking approach that accommodates these three business models and allows us to estimate the efficiency of MFIs while taking into account multiple dimensions of output. Our approach allows us to benchmark institutions with different preferences without a priori selecting a performance measure that would favor the financial or the social bottom line.

Our empirical results show that there are significant trade-offs between social and financial performance in microfinance. These trade-offs do not necessarily affect all MFIs in the same manner and can be reduced by highly efficient institutions. Preferences have a strong impact on performance as efficiency decreases when MFIs move away from their original business model, in particular when MFIs drift away from either depth or breadth of outreach. Increasing the risk of the loan portfolio reduces efficiency and lending to woman increases efficiency. Finally, our finding that multiple lending to borrowers is efficiency-enhancing may help explain the mission drift in microfinance.

Our analysis has important consequences for researchers, investors and practitioners. Research-wise, our results demonstrate that the inefficiencies found in the literature may to quite some extent be rational, and result from comparing MFIs to a benchmark that is not in line with their business model. For example, a non-profit MFI that is not very profitable, but maximizes its depth and breadth of outreach, will be very inefficient when assessed using a traditional banking approach, and highly efficient when subjected to an impact analysis. Our approach shows the importance of accounting for the multiple dimensions of microfinance, and underlines the power of the balanced scorecard.

For investors, our results should be food for thought. An investor whose main aim is to diversify and invest a share of her wealth in an MFI, should invest in one of the most efficient pure for-profit MFIs, in order to get the most 'bang for the buck.' Likewise, an NGO investing to maximize impact, should invest in an efficient non-profit MFI. Most interesting, however, is the case of the 'social' investor, who wants to do well while doing good: whereas this investor may be inclined to invest in a social for-profit MFI, our results suggest that this can be suboptimal. Instead, this investor may find higher returns (both financial and non-financial), by investing part of her wealth in an efficient for-profit MFI, and the remaining part in an efficient non-profit MFI.

Finally, for MFI practitioners the implications of our results are straightforward: in the absence of major changes in output mixes (or business models), the institutions in our sample are the most efficient when doing what they do best. For non-profit MFIs this means offering relatively expensive loans to the poor. Moving towards better off clients in an attempt to reap the benefits of economies of scale, lower risk and profit oriented investments leads to an inefficient use of resources. Whether this is the effect of subsidies, lack of managerial skills or changing market conditions, we do not know. What we do know, is that for a given output mix, all MFIs can gain by being more selective in their lending, and 
more carefully weighing the risk, background and indebtedness of their borrowers.

\section{References}

Ahlin, Christian, Jocelyn Lin, and Michael Maio. 2011. "Where does microfinance flourish? Microfinance institution performance in macroeconomic context." Journal of Development Economics, 95(2): 105 - 120.

Alam, Sk. Mahmudul. 2012. "Does Microcredit Creat Over-indebtedness?" Working paper, Institute of Microfinance (InM), Bangladesh.

Armendáriz, Beatriz, and Ariane Szafarz. 2010. "On mission drift in microfinance institutions." In The Handbook of Microfinance. Vol. 32, , ed. Beatriz Armendáriz and Marc Labie, 341-366. Singapore:World Scientific Publishing.

Bassem, Ben Soltane. 2008. "Efficiency of microfinance institutions in the Mediterranean: an application of DEA." Transition Studies Review, 15(2): 343354.

Battese, George E., and Tim J. Coelli. 1988. "Prediction of Firm-Level Technical Efficiencies with a Generalized Frontier Production Function and Panel Data." Journal of Econometrics, 38(3): 387-399.

Bogetoft, Peter. 1994. "Incentive Efficient Production Frontiers: An Agency Perspective on DEA." Management Science, 40(8): 959-968.

Bogetoft, Peter, and Dexiang Wang. 2005. "Estimating the Potential Gains from Mergers." Journal of Productivity Analysis, 23(2): 145-171-.

Brau, James C., and Gary M. Woller. 2004. “Microfinance: A Comprehensive Review of the Existing Literature." Journal of Entrepreneurial Finance and Business Ventures, 9(1): 1-26.

Conning, Jonathan. 1999. "Outreach, sustainability and leverage in monitored and peer-monitored lending." Journal of Development Economics, 60(1): 51 - 77.

Copestake, James. 2007. "Mainstreaming Microfinance: Social Performance Management or Mission Drift?" World Development, 35(10): 1721 - 1738.

Cuesta, Rafael A., and Luis Orea. 2002. "Mergers and technical efficiency in Spanish savings banks: A stochastic distance function approach." Journal of Banking Eamp; Finance, 26(12): 2231-2247.

Cull, R., A. Demirg-Kunt, and J. Murduch. 2007. "Financial Performance and Outreach: A Global Analysis Of Leading Microbanks." The Economic Journal, 117: F107-F133. 
Cull, Robert, and Connor P. Spreng. 2011. "Pursuing efficiency while maintaining outreach: Bank privatization in Tanzania." Journal of Development Economics, 94(2): $254-261$.

Cull, Robert, Asli Demirg-Kunt, and Jonathan Morduch. 2009. "Microfinance Meets the Market." The Journal of Economic Perspectives, 23(1): pp. 167-192.

D'Espallier, Bert, Isabelle Guérin, and Roy Mersland. 2011. "Women and Repayment in Microfinance: A Global Analysis." World Development, 39(5): 758 772.

Dino, Rizzi. 2000. "A utility-frontier production function approach for the efficiency measurement of multi-output public and non-profit organisations." Universitá Ca' Foscari di Venezia Working Paper 2000.08.

Dowla, A., and D. Barua. 2006. The Poor Always Pay Back: The Grameen II Story. West Hartford, CT:Kumarian Press.

Färe, R., and D. Primont. 1995. Multi-output Production and Duality: Theory and Applications. Boston:Kluwer Academic Publishers.

Färe, R., and D. Primont. 1996. "The opportunity cost of duality." Journal of Productivity Analysis, 7: 213-224.

Ghosh, Suman, and Eric Van Tassel. 2008. "A Model of Mission Drift in Microfinance Institutions." Department of Economics, College of Business, Florida Atlantic University Working Papers 08003.

Gonzalez, Adrian. 2010. "Microfinance Synergies and Trade-offs: Social versus Financial Performance Outcomes in 2008." MIX Data Brief, 7.

Gonzalez-Vega, Claudio, Mark Schreiner, Richard L Meyer, Jorge RodriguezMeza, and Sergio Navajas. 1997. "BancoSol: The challenge of growth for microfinance organizations." Microfinance for the Poor, 129-170.

Greene, Willam. 2005a. "Fixed and Random Effects in Stochastic Frontier Models." Journal of Productivity Analysis, 23: 7-32. 10.1007/s11123-004-8545-1.

Greene, William. 2005b. "Reconsidering heterogeneity in panel data estimators of the stochastic frontier model." Journal of Econometrics, 126(2): 269-303.

Greene, William. 2007. Limdep Econometric Modeling Guide. Vol. 2, Castle Hill, Australia:Econometric Software.

Gutiérrez-Nieto, Begoña, Carlos Serrano-Cinca, and C Mar Molinero. 2007a. "Microfinance institutions and efficiency." Omega, 35(2): 131 - 142.

Gutiérrez-Nieto, Begoña, Carlos Serrano-Cinca, and C Mar Molinero. 2007b. "Social efficiency in microfinance institutions." Journal of the Operational Research Society, 60(1): 104-119. 
Handy, Femida, and Eliakim Katz. 1998. "The Wage Differential between Nonprofit Institutions and Corporations: Getting More by Paying Less?" Journal of Comparative Economics, 26(2): 246-261.

Haq, Mamiza, Michael Skully, and Shams Pathan. 2010. "Efficiency of microfinance institutions: a data envelopment analysis." Asia-Pacific Financial Markets, 17(1): 63-97.

Hassan, M Kabir, and Benito Sanchez. 2009. "Efficiency analysis of microfinance institutions in developing countries." Networks Financial Institute at Indiana State University Working Paper, 12.

Hermes, Niels, Robert Lensink, and Aljar Meesters. 2011. "Outreach and Efficiency of Microfinance Institutions." World Development, 39(6): 938 - 948.

Hirth, Richard A. 1999. "Consumer information and competition between nonprofit and for-profit nursing homes." Journal of Health Economics, 18(2): 219240.

Hulme, David, Paul Mosley, et al. 1996. Finance against poverty: Volume 1. Routledge.

Kodde, D A, and F C Palm. 1986. "Wald Criteria for Jointly Testing Equality and Inequality Restrictions." Econometrica, 54: 1243-1248.

Krishnaswamy, Karuna. 2007. "Competition and Multiple Borrowing in the Indian Microfinance Sector." Financial Management, , (September).

Kroll, Yoram, Haim Levy, and Harry M. Markowitz. 1984. "Mean-Variance Versus Direct Utility Maximization." The Journal of Finance, 39(1): 47-61.

Kumbhakar, Subal C., and C. A. Knox Lovell. 2000. Stochastic frontier analysis. Cambridge University Press.

Lakdawalla, Darius, and Tomas Philipson. 2006. "The nonprofit sector and industry performance." Journal of Public Economics, 90(89): 1681-1698.

Leibenstein, Harvey. 1966. "Allocative Efficiency vs. "X-Efficiency"." The American Economic Review, 56(3): 392-415.

Leibenstein, Harvey. 1978. "X-Inefficiency Xists: Reply to an Xorcist." The American Economic Review, 68(1): 203-211.

Lin, William, G. W. Dean, and C. V. Moore. 1974. “An Empirical Test of Utility vs. Profit Maximization in Agricultural Production." American Journal of Agricultural Economics, 56(3): 497-508. 
Malani, Anup, Tomas Philipson, and Guy David. 2003. "Theories of Firm Behavior in the Nonprofit Sector. A Synthesis and Empirical Evaluation." In The Governance of Not-for-Profit Organizations. NBER Chapters, 181-216. National Bureau of Economic Research, Inc.

Mersland, Roy. 2009. "The Cost of Ownership in Microfinance Organizations." World Development, 37(2): $469-478$.

Mersland, Roy, and Reidar Øystein Strøm. 2009. "Performance and governance in microfinance institutions." Journal of Banking E Finance, 33(4): 662 - 669.

Mersland, Roy, and Reidar Øystein Strøm. 2010. "Microfinance Mission Drift?" World Development, 38(1): $28-36$.

Mersland, Roy, and Reidar Øystein Strøm. 2011. "What drives the microfinance lending rate?" Working Paper.

Morduch, Jonathan. 1999a. "The Microfinance Promise." Journal of Economic Literature, 37(4): pp. 1569-1614.

Morduch, Jonathan. 1999b. "The role of subsidies in microfinance: evidence from the Grameen Bank." Journal of Development Economics, 60(1): 229 - 248.

Morduch, Jonathan. 2000. "The Microfinance Schism." World Development, 28(4): $617-629$.

Nawaz, Ahmad, Marek Hudon, and Benazir Basharat. 2011. "Does efficiency lead to lower interest rates? A new perspective from microfinance." Second European Research Conference in Microfinance, Groningen, The Netherlands.

Pauly, Mark V. 1987. "Nonprofit Firms in Medical Markets." The American Economic Review, 77(2): 257-262.

Perelman, Michael. 2011. "Retrospectives: X-Efficiency." The Journal of Economic Perspectives, 25(4): 211-222.

Roberts, Peter W. 2012. "The Profit Orientation of Microfinance Institutions and Effective Interest Rates." World Development, , (0): -.

Schicks, Jessica. 2010. "Microfinance Over-Indebtedness: Understanding its drivers and challenging the common myths." ULB - Universite Libre de Bruxelles Working Papers CEB 10-048.

Schreiner, Mark. 2002. "Aspects of outreach: a framework for discussion of the social benefits of microfinance." Journal of International Development, 14(5): 591603.

Sealey, C. W., Jr., and James T. Lindley. 1977. "Inputs, Outputs, and a Theory of Production and Cost at Depository Financial Institutions." The Journal of Finance, 32(4): 1251-1266. 
Smith, Vernon L. 1976. "Experimental Economics: Induced Value Theory." The American Economic Review, 66(2): 274-279.

Stigler, George J. 1976. "The Xistence of X-Efficiency." The American Economic Review, 66(1): 213-216.

Von Pischke, J. D. 1996. "Measuring the trade-off between outreach and sustainability of microenterprise lenders." Journal of International Development, 8(2): 225-239. 


\section{Appendix}

Table A.1-: Output distance frontier results

\begin{tabular}{|c|c|c|}
\hline Variable & Parameter & Std.Error \\
\hline \multicolumn{3}{|c|}{ Deterministic Component of Stochastic Frontier Model } \\
\hline constant & $2.6950^{* * * *}$ & $(0.0413)$ \\
\hline $\ln$ (number of loans) & $-1.0385^{* * *}$ & $(0.0152)$ \\
\hline $\ln ($ yield $)$ & $0.0455^{* * *}$ & $(0.0075)$ \\
\hline $\ln$ (financial expenses) & $-0.0281^{* * *}$ & $(0.0040)$ \\
\hline $\ln$ (adminstrative expenses) & 0.0165 & $(0.0236)$ \\
\hline $\ln$ (personnel expenses) & $-0.2002^{* * *}$ & $(0.0276)$ \\
\hline $1 / 2 \ln (\text { number of loans })^{2}$ & $0.0403^{* * *}$ & $(0.00418)$ \\
\hline $1 / 2 \ln (\text { yield })^{2}$ & $-0.0235^{* * *}$ & $(0.0017)$ \\
\hline $1 / 2 \ln \left({\text { financial expenses })^{2}}^{2}\right.$ & $0.0553^{* * *}$ & $(0.0014)$ \\
\hline $1 / 2 \ln (\text { administrative expenses })^{2}$ & 0.0007 & $(0.0061)$ \\
\hline $1 / 2 \ln$ (personnel expenses) $^{2}$ & $0.0925^{* * *}$ & $(0.0067)$ \\
\hline $\ln ($ number of loans $) \times \ln ($ yield $)$ & $0.0016^{* * *}$ & $(0.0001)$ \\
\hline $\ln ($ number of loans $) \times \ln$ (financial expenses) & $0.0005^{* * *}$ & $(0.0001)$ \\
\hline $\ln$ (number of loans) $\times \ln ($ adminstrative expenses) & $0.0010^{* * *}$ & $(0.0003)$ \\
\hline $\ln ($ number of loans) $\times \ln$ (personnel expenses) & -0.0009 & $(0.0003)$ \\
\hline $\ln ($ yield $) \times \ln ($ financial expenses $)$ & $-0.0003^{* * *}$ & $(0.0001)$ \\
\hline $\ln ($ yield $) \times \ln ($ administrative expenses $)$ & 0.0002 & $(0.00016)$ \\
\hline $\ln ($ yield $) \times \ln ($ personnel expenses $)$ & 0.0002 & $(0.0002)$ \\
\hline $\ln$ (financial expenses) $\times \ln$ (administrative expenses) & -0.0002 & $(0.0002)$ \\
\hline $\ln ($ financial expenses $) \times \ln ($ personnel expenses $)$ & $-0.0003^{*}$ & $(0.0002)$ \\
\hline $\ln ($ administrative expenses $) \times \ln$ (personnel expenses) & $-0.0008^{* *}$ & $(0.0002)$ \\
\hline $\ln$ (number of loans) $\times D_{\text {Bank }}$ & 0.0002 & $(0.0032)$ \\
\hline $\ln$ (number of loans) $\times D_{\text {Cooperative or credit union }}$ & 0.0021 & $(0.0030)$ \\
\hline $\ln$ (number of loans) $\times D_{\text {Non-bank financial institution }}$ & $0.0105^{* * *}$ & $(0.0028)$ \\
\hline $\ln$ (number of loans) $\times D_{\text {Rural bank }}$ & 0.0093 & $(0.0104)$ \\
\hline $\ln ($ yield $) \times D_{\text {Bank }}$ & -0.0010 & $(0.0020)$ \\
\hline $\ln ($ yield $) \times D_{\text {Cooperative or credit union }}$ & $0.0044^{* * *}$ & $(0.0018)$ \\
\hline $\ln ($ yield $) \times D_{\text {Non-bank financial institution }}$ & 0.0007 & $(0.0018)$ \\
\hline $\ln ($ yield $) \times D_{\text {Rural bank }}$ & -0.0068 & $(0.0052)$ \\
\hline $\ln ($ financial expenses $) \times D_{\text {Bank }}$ & 0.0022 & $(0.0023)$ \\
\hline $\ln$ (financial expenses) $\times D_{\text {Cooperative or credit union }}$ & $-0.0222^{* * *}$ & $(0.0019)$ \\
\hline $\ln$ (financial expenses $) \times D_{\text {Non-bank financial institution }}$ & $-0.0082^{* * *}$ & $(0.0013)$ \\
\hline $\ln$ (financial expenses) $\times D_{\text {Rural bank }}$ & 0.0039 & $(0.0033)$ \\
\hline $\ln$ (adminstrative expenses) $\times D_{\text {Bank }}$ & $0.0108^{*}$ & $(0.0060)$ \\
\hline $\ln$ (adminstrative expenses $) \times D_{\text {Cooperative or credit union }}$ & $0.0110^{* * *}$ & $(0.0037)$ \\
\hline $\ln ($ adminstrative expenses $) \times D_{\text {Non-bank financial institution }}$ & 0.0083 & $(0.0052)$ \\
\hline $\ln ($ adminstrative expenses $) \times D_{\text {Rural bank }}$ & 0.0134 & $(0.0161)$ \\
\hline $\ln$ (personnel expenses) $\times D_{\text {Bank }}$ & $-0.0226^{* * *}$ & $(0.0052)$ \\
\hline $\ln$ (personnel expenses) $\times D_{\text {Cooperative or credit union }}$ & $-0.0086^{* *}$ & $(0.0041)$ \\
\hline $\ln$ (personnel expenses $) \times D_{\text {Non-bank financial institution }}$ & $-0.0112^{* *}$ & $(0.0052)$ \\
\hline $\ln ($ personnel expenses $) \times D_{\text {Rural bank }}$ & -0.0185 & $(0.0195)$ \\
\hline \multicolumn{3}{|c|}{ Variance parameters for compound error } \\
\hline$\lambda$ & $2.5600^{* * *}$ & $(0.2611)$ \\
\hline$\sigma_{u}$ & $0.3130^{* * *}$ & $(0.0196)$ \\
\hline $\begin{array}{l}\text { te: Log likelihood function value is } 1678.45564 ; \text { Kodde and } \mathrm{P} \\
5 \% \%=10.371 \text {, at } 99 \%=14.325 \text {. To correct for spurious interac } \\
\text { en transformed following the Frisch-Waugh theorem. To cont } \\
\text { t explain } \mu \text { have been orthogonalized. } \lambda=\sigma_{u} / \sigma_{v} \text {, i.e., the rat } \\
\text { viation of (untransformed) inefficiency. }\end{array}$ & $\begin{array}{l}\text { test for wro } \\
\text { all variabl } \\
\text { ible multicc } \\
\text { ciency and } n\end{array}$ & $\begin{array}{l}\text { ed resid } \\
\text { ranslog } \\
\text { the vari }\end{array}$ \\
\hline
\end{tabular}


Table A.2-: Group composition criteria

\begin{tabular}{|c|c|c|}
\hline Characteristic & Group & Sorting criteria \\
\hline \multirow{4}{*}{$\begin{array}{l}\text { Breadth of } \\
\text { outreach }\end{array}$} & Small Breadth & Number of Borrowers $<10,000$ \\
\hline & Medium Breadth & Number of Borrowers 10,000 to 30,000 \\
\hline & Large Breadth & Number of Borrowers $>30,000$ \\
\hline & Low end & Depth $<20 \%$ OR average loan size $<$ USD 150 \\
\hline \multirow{3}{*}{$\begin{array}{l}\text { Depth of } \\
\text { outreach }\end{array}$} & Broad & Depth between $20 \%$ and $149 \%$ \\
\hline & High end & Depth between $149 \%$ and $250 \%$ \\
\hline & Small Business & Depth over $250 \%$ \\
\hline
\end{tabular}

Note: Depth = Avg. Loan Balance per Borrower/GNI per capita. Criteria defined at http://www. mixmarket. org/about/faqs\#calculations1 